(2,01) U.S. GEOLOURCAL SURUEY.

R29

n. $74-90$

[REPDRTS - OPEN FILE SERIES]

This openfile package contains experimental, working materials

developed for a test site in southern Arizona, specifically the Ajo quadrangle of the standard 1:250,000-scale series of maps. The 1and use information in this package was primarily derived from 1971 highaltitude aerial photography. The experimental nap is computer-plotted with polygons representative of land use patterns; ten acres is the minimum. size of actual land use depicted on the map by the polygons. Accuracy for the land use map has been verified by field checking to be higher than $95 \%$ in both urban and agricultural areas. Land use patterns were delineated according to the classification system proposed by USGS Circular 671. In addition to the land use map, a transparent composite overlay of the black, gray, and red plates for the quadrangle is supplied to satisfy locational information.

Along with the chosen map output of land use, the computer data bank and this package contain other factors which include: drainage basin, census tract, and soll information, which vere obtained from other agencies. The analyses of these factors are contained in computercalculated compilations called area summaries. Summaries for each of the specific factors tabulate the total polygon areas of various types of categorles delineated within each factor. The calculation figures show the occupied land area in acres, hectares, and percentage for erch category in the quadrangle; the area summaries are provided for each factor. Listed on each respective area summary is an explanation of the code symbols representing each category within the different Eactors.

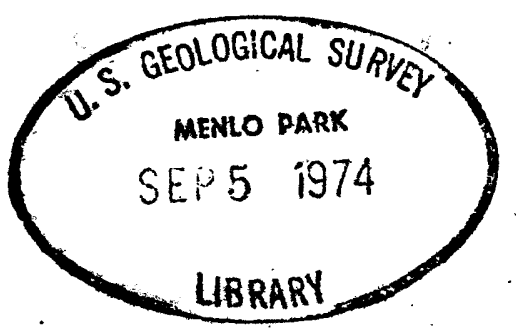




\section{drainage basins}

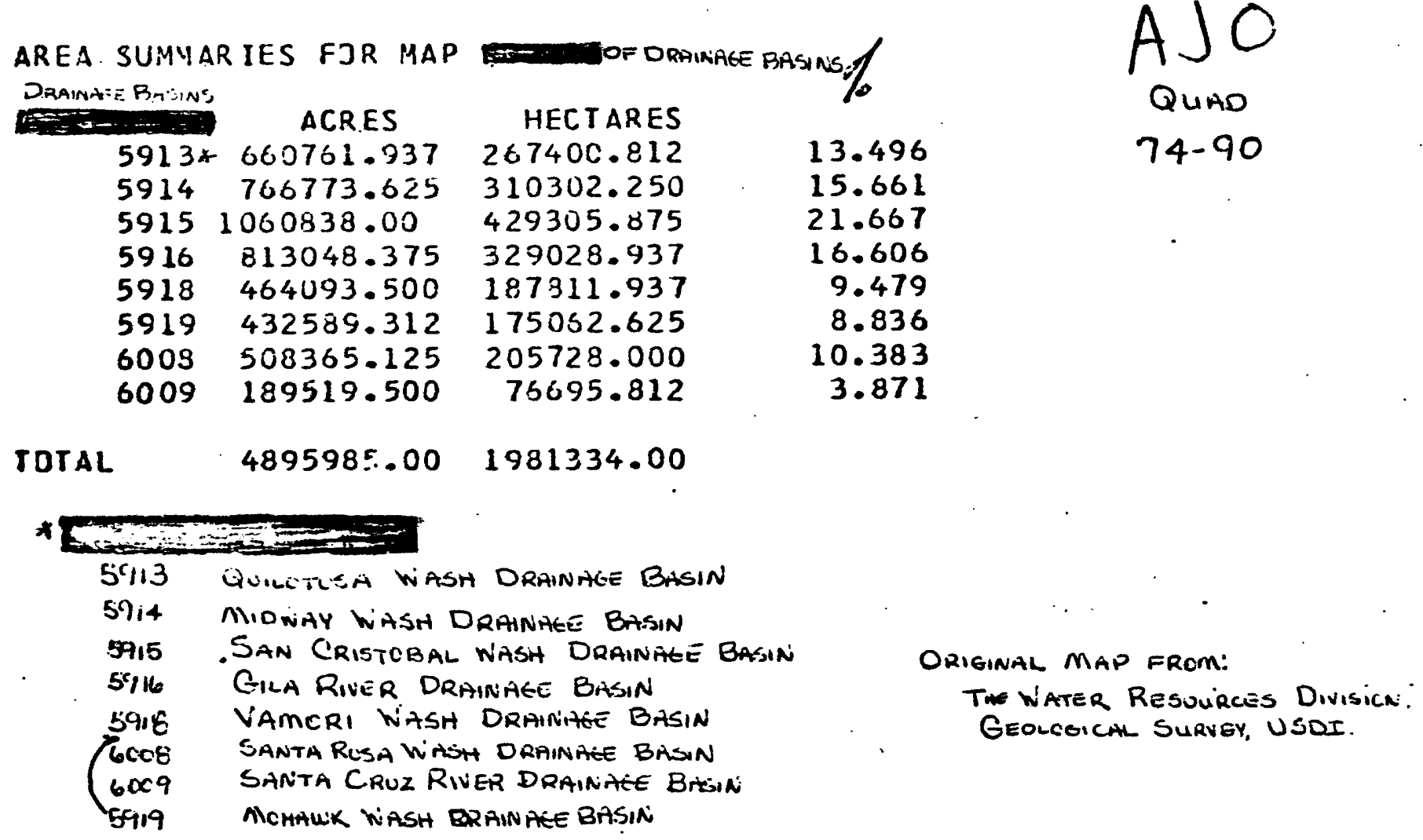

Experimental Tabulation from the USGS Data Bank for Land Use and Related Factors. 
ACRES HECTARES

* arr 2000345802.00

4211.473443 .375

4211

4213

4215

.4216

4217

4218

4221

4222

4224

4225

TDTAL

473443.375

463469.375

106773.312

94289.812

39004.080

257890.562

151522.875

13069.945

30065.176

61624.025

1399646.00

191595.687

187559.375

104364.562

5149729.00
43209.621

38157.730

15784.633

61319.125

5289.219

12166.941

24938.598

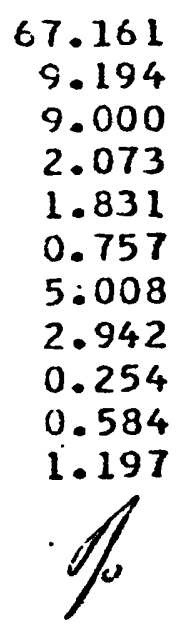

2084021.00
$A J C$

Gurto

74-90
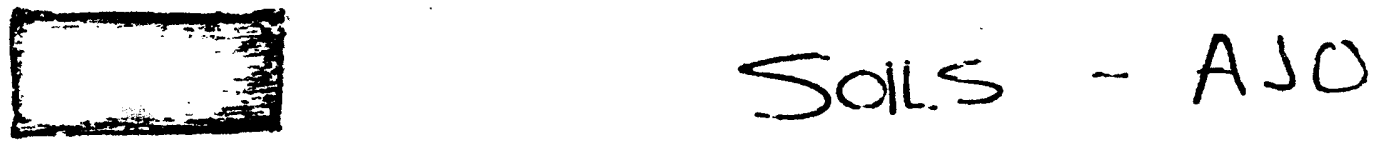

MARICOPA CCINTY

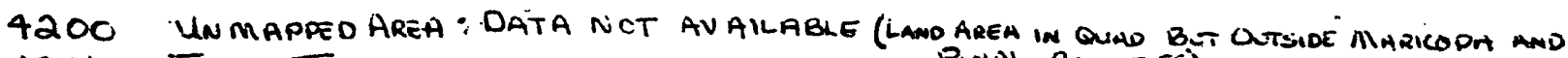

4211 . Trpic Torrifluients

P.NAL COUNTIES)

$4213^{\circ}$ TYPIC Calciorthios

4215 LITHIC TORRICRTHENTS

4217

SHALLOW SCLS CLER UNWEHTHEREO ANOICR WEATHERED BEORLCK

4216

STCNY AND ROCKY MOULYTHINICIS LILS OVER EECLCGIC MATERIALS

Pinal County

42.21 SOLS OF THE FLOOD PLAINS

4222 SOLS CF THE VALLY SLCPES

4224

4225

ROCK LAND

ORIGINAL MAP FROM:

THE Soil Conseruaticn Seruice. USOA.

Experimental Tabulation from the USGS Data Bank for Land Use and Related Factors. 
AREA SUMMARIES FOR MAP

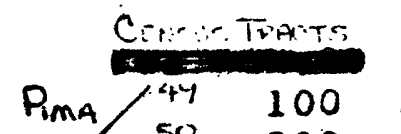

ACRES

847134. 812

1018.908

8d 7371.562

300

3157233.00

TOTAL
$4892758.00 \quad 1980028.00$

FIOF CENSUS TRACTS

HECTARES

342823.250

412.337

359106.500

1277686.00

\section{Orieintl Map from:}

The Bureau of the Census. US DEPT. OF COMMERCE. Censls of Population 1970.

Experimental Tabulation from the USGS Data Bank for Land Use and Related Factors. 


\section{Land-Usè Classification System for Use $\therefore \quad$ With Remote Sensor Data \\ Levell \\ Level II \\ O1. Urban and Built-up Land.}

6

02. Agricultural Land.

03. Rarigeland.

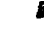

94. Forest Land.

.

05. Water.

06. Nonforested Wetland.

07. Barren Land.

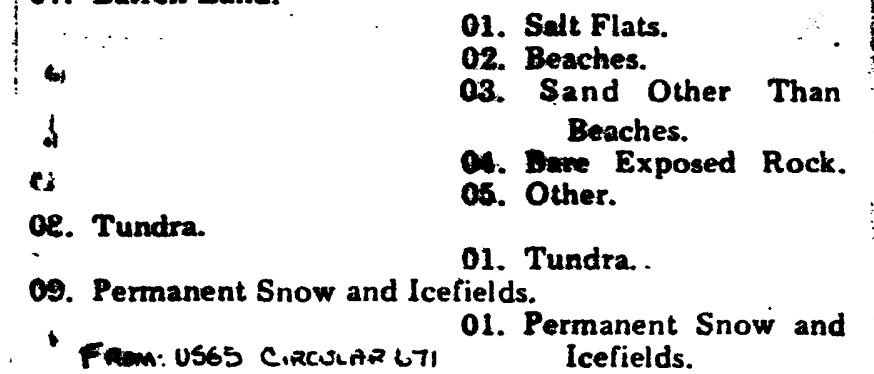

01. Residential.

02. Commercial and services.

03. Industrial.

04. Extractive.

05. Transportation, Communications, and Utilities.

06. Institutional.

07. Strip and Clustered Settlement.

08. Mixed.

09. Open and Other.

01. Cropland and Pasture.

02. Orchards, Groves. Bush Fruits. Vinesards, and Horticultural Areas.

03. Feeding Operations.

04. Other.

01. Grass.

02. Savannas (Palmetto Prairies).

03. Choparral.

04. Desert Shrub.

01. Deciduous.

02. Evergreen (Coniferous and Other)

03. Mixed.

01. Streams and Water- ways.

02. Lakes.

03. Reservoirs.

04. Bays and Estuaries.

05. Other.

01. Vegetated.

02. Bare.

01. Selt Flats.

02. Beaches.

Sand Other Than

Beaches.

Exposed Rock.

01. Tundra.

01. Permanent Snow and Icefields. 



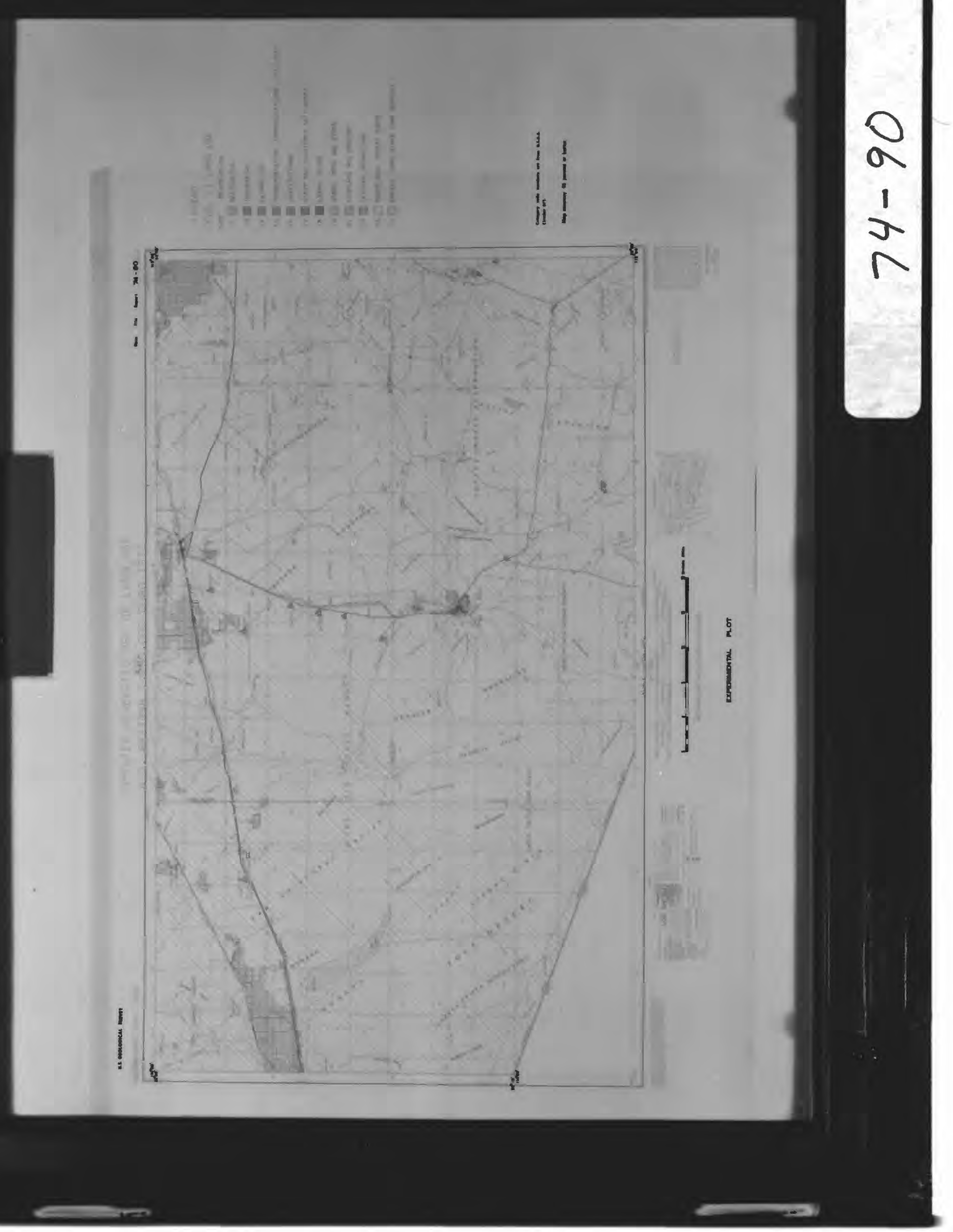

